\section{International Scientific Journal Theoretical \& Applied Science}

p-ISSN: 2308-4944 (print)

e-ISSN: 2409-0085 (online)

Year: 2015

Issue: 02

Volume: 22

Published: 28.02 .2015

\author{
http://www.T-Science.org
}

Konstantin Konstantinovich Tkachuk doctor of technical sciences, as. professor, Head of the Environmental Engineering Department IEE NTUU “KPI”, Ukraine osipova_tetiana@ukr.net

SECTION 6. Metallurgy and energy.

\title{
INVESTIGATION OF METHANE EMISSION DURING DECOMPOSITION OF ORGANIC WASTE
}

\begin{abstract}
The article deals with the current state of municipal solid waste MSW management in Ukraine. Most of the waste buried in landfills and dumps. MSW landfills in the country occupy a large area, the leachate which produced in landfills can contaminate groundwater and harmful gases cause air pollution and contribute to the greenhouse effect. The gas which is formed during the decomposition of organic waste in landfills called landfill gas whose main ingredient is methane. Methane is formed in four steps and requires certain conditions, such as temperature, composition of the waste, etc. An experiment on the formation of biogas from four waste mixtures was conducted and dependences of landfill gas production on waste composition were built. Also an experiment of landfill gas production with a mixture of proteins and fats mixture in different temperature regimes with and without stirring the mixture was conducted.

Key words: biogas, municipal solid waste, landfill, methane.

Language: Russian

Citation: Tkachuk KK (2015) INVESTIGATION OF METHANE EMISSION DURING DECOMPOSITION OF ORGANIC WASTE. ISJ Theoretical \& Applied Science 02 (22): 75-81. doi: http://dx.doi.org/10.15863/TAS.2015.02.22.13
\end{abstract}

\section{ИССЛЕДОВАНИЕ ЭМИССИИ МЕТАНА ПРИ РАЗЛОЖЕНИИ ОРГАНИЧЕСКИХ ОТХОДОВ}

Аннотация: В статье рассмотрено текущее состояние в сфере обращзения с отходами в Украине. Большая часть отходов захоронена на полигонах ТБО и свалках. Полигоны на территории страны занимают большие территории, фильтрат, образующийся на свалках, может загрязнять подземные воды, а вредные газы вызывают загрязнение атмосферы и способствуют парниковому эффекту. Газ, который образуется на полигоне при разложении органики, называется свалочным газом, основным компонентом которого является метан. Образование метана происходит в четыре стадии и требует определенных условий, таких как температурный режим, состав отходов и т.д. Был проведен эксперимент по образованию биогаза из четырех смесей отходов и построены зависимости образование биогаза от состава отходов. Также проводился эксперимент по получению биогаза для смеси с белками и смеси с жирами при разных температурных режимах с наличием и без наличия перемешивания смеси.

Ключевые слова: биогаз, твердые бытовые отходы, полигон ТБО, метан.

АКТУАЛЬНОСТЬ РАБОТЫ. Наиболее распространенным способом обращения с отходами в Украине является их захоронение на полигонах твердых бытовых отходов (ТБО) или на свалках. При разложении органических отходов образуется свалочный газ, основным компонентом которого является метан, который создает в 21 раз больше парниковый эффект, чем диоксид углерода. При среднем выходе свалочного газа $100 \mathrm{~m}^{3} / \mathrm{T}$ ТБО, средняя скорость его выхода принимается, как правило, 5 м³/т ТБО в год. Эта цифра подтверждается данными по эксплуатации 86 систем сбора свалочного газа в различных странах. Газ горючий и имеет теплотворную способность около 18 МДж/ $\mathrm{m}^{3}$. Скорость разложения ТБО зависит от вида отходов и физико-химических условий в теле свалки (влажности, температуры, кислотности и т.д.). Полигоны с большим содержанием бумаги, картона и древесины, характерные для развитых стран, генерирующих метан в течение 20 лет и более. Полигоны ТБО в развивающихся странах 
образуют газ более интенсивно (10-15 лет). Это объясняется тем, что ТБО в таких странах содержат пищевые отходы, которые более легко разлагаются [10].

Украина занимает первое место в мире по количеству мусора на душу населения. В Украине более 160 тыс. гектаров земли переданы под полигоны для мусора, на которых хранится около 35 млрд. тонн отходов. При этом ежегодно в стране создается 12000 незаконных свалок, поскольку полигонов для мусора недостаточно. Большинство существующих полигонов уже исчерпали свой ресурс, а мусорные свалки стали фактором антропогенной нагрузки на окружающую среду. Среди них наиболее распространены полигоны ТБО средней опасности, имеющих смешанный состав из мелкого и среднего мусора, складируются в карьере, а также в карьере с насыпью. Для возведения их негативного воздействия к минимуму, необходимо неукоснительно соблюдать предварительно разработанного плана рекультивации. Целесообразным является сбор биогаза с его дальнейшим использованием в промышленных целях, это снизит выброс загрязняющих атмосферу компонентов и позволит снизить долю использования дорогостоящего топлива в целом.

Основной целью работы является оценка влияния температуры, состава отходов и их перемешивания на образование метана.

\section{МАТЕРИАЛЫ И РЕЗУЛЬТАТЫ}

ИССЛЕДОВАНИЯ. В связи С ростом промышленности и мирового населения, количество отходов ежегодно растет. Не смотря на новые разработки в сфере обращения с отходами, основным способом остается их захоронение на полигонах. Это вызвано просототой и дешевизной этого метода. При биоразложении органической составляющей отходов образуется биогаз, 50-60 \% которого составляет метан [9, с. 482]. Накопление биогаза на полигонах может быть, опасным, так как он легковоспламеним, кроме того метан является парниковым газом. С другой стороны, биогаз является цененым углеводородным топливом, что особеннно важно при нехватке энергоресурсов. В зависимости от количества и состава отходов, температуры в теле полигона и других характеристик свалки, образуется разное количество биогаза.

Твердые бытовые отходы представляют собой сложную гетерогенную смесь. По морфологическим признаком ТБО в настоящее время состоит из следующих компонентов:

- бумага - газеты, журналы, упаковочные материалы;

- пластмассы;

- пищевые и растительные отходы;

- различные металлы (цветные и черные);

- стекло;

- текстиль;

- древесина;

- кожа, резина;

- кости.

Фракционный состав ТБО (массовое содержание компонентов, проходящих через сита с ячейками разного размера) влияет как на сбор и транспортировку отходов, так и на технологии их дальнейшей переработки, сортировки.

Одна из возможных схем сбора биогаза на полигоне приведена на рис.1 [1, с.26] .

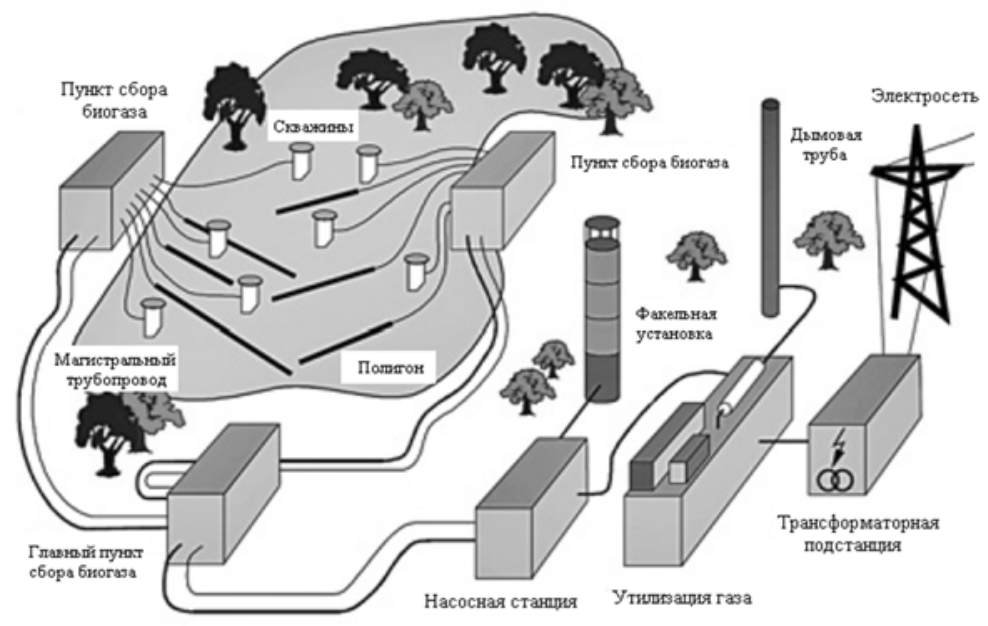

Рисунок 1 - Система сбора биогаза на полигоне ТБО.

В настоящее время существует несколько классификаций полигонов ТБО, носящие стихийный или официальный характер возникновения, с помощью которых можно
ISPC European Technology in Science,

Malmö, Sweden 
определить интенсивность и характер загрязнений окружающей среды.

По характеру складированного мусора полигоны делятся на промышленные, бытовые и смешанного типа. Важной характеристикой свалок является их размер.

Еще одно деление существующих полигонов ТБО касается способа складирования мусора. По этому критерию выделяют насыпные полигоны, карьерные и карьерные с последующим образованием насыпи. Все свалки также имеют разделение по степени опасности: потенциально опасные, средней опасности и относительно безопасные полигоны.

Химический состав ТБО необходим для определения качества получаемого при переработке ТБО компоста или биогаза. Состав ТБО отличается в разных странах, городах. Он зависит от многих факторов, включая благосостояние населения, климат и благоустройство. На склад мусора существенно влияет система сбора в городе стеклотары, макулатуры и т. Д. ОН может меняться в зависимости от сезона, погодных условий. Так на осень приходится увеличение количества пищевых отходов, что связано с большим употреблением овощей и фруктов в рационе питания. А зимой и весной сокращается содержание мелкого отсева (уличного). С течением времени состав ТБО несколько меняется. Увеличивается доля бумаги и полимерных материалов. А с переходом на централизованное теплоснабжение практически исчезает с ТБО угля и шлак.

С точки зрения элементного содержания основу ТБО составляют компоненты, содержащие углерод. Именно они формируют экологическую нагрузку при размещении ТБО в окружающей среде.

Процесс преобразования органического вещества в биогаз в анаэробных условиях под действием различных бактерий (метановое брожение или биометаногенез) известен давно. Серьезные исследования метанового сбраживания с точки зрения химизма и кинетики этого процесса проводились применительно к осадкам городских сточных вод. В большинстве исследований подтверждается, что разложение органического вещества на полигонах ТБО протекает подобно брожению упомянутых осадков, проведенного в специальных метантенках. Анаэробные процессы и выделение биогаза на полигоне начинаются после уплотнения (механического и естественного) отходов при существовании условий нормальной жизнедеятельности микроорганизмов, участвующих в процессе брожения органического вещества. В процессе биохимического разложения отходов, кроме биогаза, в теле полигона образуется фильтрат токсический раствор, который должен собираться, очищаться и частично подаваться (возвращаться) в тело полигона для создания в последнем необходимой влажности. При этом не только снижается пожароопасность, но и ускоряется ферментация ТБО.

Биохимическая деструкция органики в теле полигона и местах захоронения ТБО, которая объясняет стадии разложения органических составляющих ТБО, может быть представлена следующими теоретическими объяснениями. Ежедневное перекрытия ТБО слоями инертного грунта, с одной стороны, защищает атмосферу от загрязнения, а с другой - прекращает доступ кислорода к ТБО в теле полигона. Однако ТБО является пористым материалом, поэтому, запаса воздуха в порах достаточно, чтобы первое время (до 3 месяцев) в теле полигона протекали аэробные процессы. При этом происходит разогрев тела полигона до температуры $20-40{ }^{\circ} \mathrm{C}$ и основными продуктами аэробных процессов является диоксид углерода и вода. Постепенно, по мере использования запасов кислорода в порах ТБО активность аэробных процессов падает и в ТБО, начинают преобладать анаэробные процессы, вызываемые деятельностью анаэробных микроорганизмов.

Эти процессы идут медленно и, преимущественно в пищевых отходах и других органических соединениях Анаэробные микроорганизмы не используют молекулярный кислород воздуха для окисления органических веществ, а получают необходимую для жизнедеятельности энергию в результате расщепления органических веществ. Эти процессы получили название анаэробного сбраживания. Анаэробное сбраживание - это комплекс биохимических процессов, превращающих органические соединения ТБО в стабильный продукт. Как биохимический процесс он лимитируется микробными популяциями и факторами внешней среды и условно может быть разделен на несколько стадий. Теоретически анаэробные биохимические реакции, происходящие в теле полигона ТБО при отсутствии кислорода, можно представить в следующем виде: 
- первая стадия

$$
\left(\mathrm{C}_{6} \mathrm{H}_{10} \mathrm{O}_{5}\right)+\mathrm{nH}_{2} \mathrm{O} \stackrel{\text { микроорганизмы }}{\longrightarrow} \mathrm{n}\left(\mathrm{C}_{6} \mathrm{H}_{10} \mathrm{O}_{6}\right) \text {. }
$$

На первой стадии путем биохимического расщепления (гидролиза) высокомолекулярные соединения разлагаются на низкомолекулярные.

- вторая стадия

$$
\mathrm{n}\left(\mathrm{C}_{6} \mathrm{H}_{10} \mathrm{O}_{6}\right) \stackrel{\text { микроорганизмы }}{\longrightarrow} 2 \mathrm{n}\left(\mathrm{CH}_{3} \mathrm{CH}_{2} \mathrm{OH}\right)+2 \mathrm{n}\left(\mathrm{CO}_{2}\right)+57 \text { ккал. }
$$

Сбраживание без доступа кислорода приводит к образованию этанола, диоксида углерода и выделению небольшого количества тепла (в 12 раз меньше, чем при аэробном процессе). Поэтому в отличие от быстрого

- третья стадия

$$
2 \mathrm{n}\left(\mathrm{CH}_{3} \mathrm{CH}_{2} \mathrm{OH}\right)+\mathrm{n}\left(\mathrm{CO}_{2}\right) \stackrel{\text { микроорганизмы }}{\longrightarrow} 2 \mathrm{n}\left(\mathrm{CH}_{3} \mathrm{COOH}\right)+\mathrm{n}\left(\mathrm{CH}_{4}\right) \text {. }
$$

На третьей стадии с участием микроорганизмов происходит дальнейшее разложение органики с получением органических кислот и их солей, а также небольшого обеззараживания при аэробном процессе процесс обеззараживания ТБО при анаэробном сбраживании достаточно медленный и требует больших затрат времени.

- четвертая стадия

$$
2 \mathrm{n}\left(\mathrm{CH}_{3} \mathrm{COOH}\right) \stackrel{\text { метанові бактерії }}{\longrightarrow} 2 \mathrm{n}\left(\mathrm{CH}_{4}\right)+2 \mathrm{n}\left(\mathrm{CO}_{2}\right) \text {. }
$$

Четвертая стадия называется стадией метанового брожения, при котором органика превращается в $\mathrm{CH}_{4}$ и $\mathrm{CO}_{2}$, а из свободных $\mathrm{CO}_{2}$ и $\mathrm{H}_{2}$ также образуется метан. Метанобразующие бактерии могут существовать только в анаэробных условиях, для их воспроизведения необходимо больше времени, чем для кислотообразующих бактерий [11, с.60-62] .

Скорость анаэробного сбраживания зависит от метаболической активности метановых бактерий, которая, в свою очередь зависит от:

- температуры (оптимум при температуре $\left.33-54{ }^{\circ} \mathrm{C}\right)$;

- отношение $\mathrm{C} / \mathrm{N}$ (оптимум в диапазоне 1016);

- величины рН (оптимум около 6,5)

и других внешних условий, например, наличия в ТБО солей тяжелых металлов, аммиака, нитратов, сульфатов, антибиотиков и др. При отклонении от указанных выше оптимальных условий увеличивается образование летучих кислот и уменьшается выход метана.

Bce указанные стадии биохимических процессов осуществляются с участием различных групп бактерий (микроорганизмов). Так первые две стадии осуществляются при участии ферментативных бактерий, относящихся к родам Pseudomonas, Micrococcus, Clostridium и др. Эти количества метана $\left(\mathrm{CH}_{4}\right)$. В реальных условиях разложения рядовых ТБО в небольших количествах также образуются: сероводород $\left(\mathrm{H}_{2} \mathrm{~S}\right)$, аммиак $\left(\mathrm{NH}_{3}\right)$, водород $\left(\mathrm{H}_{2}\right)$ и другие газы.

бактерии относятся к анаэробным, они быстро растут (организмы, которые живут за счет энергии расщепления химических соединений в условиях отсутствия свободного кислорода) при оптимальном значении $\mathrm{pH}=6,5-7,6$. Ацетогенная стадия осуществляется двумя группами ацетогенных бактерий: первая образует ацетат с выделением водорода, вторая приводит к образованию уксусной кислоты путем использования водорода для восстановления углекислого газа $[11$, с.60-61]. На метаногенной стадии метанобразующие бактерии (метаногены) образуют метан путем расщепления уксусной кислоты и восстановления углекислоты водородом. Метановые бактерии очень чувствительны к присутствию в среде растворенного кислорода и нитратов (для них губительна концентрация кислорода, равной 0,01 мг/л), оптимальное значение $\mathrm{pH}$ среды для этих бактерий 7-7,5.

Метановое брожение происходит при температуре 4-70 ${ }^{\circ} \mathrm{C}$, при этом может иметь место психрофильный режим сбраживания $(\mathrm{t}=4$ $\left.25^{\circ} \mathrm{C}\right)$, мезофильный $\left(\mathrm{t}=30-35{ }^{\circ} \mathrm{C}\right)$ и термофильный $\left(\mathrm{t}=50-70^{\circ} \mathrm{C}\right)$. Для обеспечения нормальной жизнедеятельности метаногенов необходимо соблюдение следующих условий: постоянство температуры и давления, строгий 
анаэробный процесс, нейтральное или слабощелочная среда, отсутствие света, оптимальная влажность массы (60-70\%), оптимальное соотношение водорода и азота, углерода и азота (1: 16 1: 19).

Количественный выход биогаза и его состав определяют отдельные компоненты органического вещества: углеводы, белки и жиры при их взаимодействии с влагой и бактериями в соответствии со стехиометрическими уравнениями реакций брожения.

Углеводы представлены в основном целлюлозой, гемицеллюлозой и лигнином (основными веществами стенки растительной клетки). Более 90\% этих веществ содержится в древесных отходах; в основе бумажных и картонных отходов также лежит целлюлоза; натуральные волокна текстиля (хлопок, лен) на $85-90 \%$ состоят из целлюлозы, часть волокон животного происхождения состоит из белков; пищевые отходы растительного происхождения содержат целлюлозу и белки, а животного происхождения в основном состоят из белков и жиров (в мясных отходах более $50 \%$ белков).

Существует множество факторов, влияющих на количество метана и скорость его образования. Для метаногенеза необходим определенный температурный режим. Этот процесс может происходить при температурах от 20 до $65^{\circ} \mathrm{C}$, но максимальная интенсивность метанообразования, как показали эксперименты, наблюдается в диапазоне $30-40{ }^{\circ} \mathrm{C}$.

Основной целью работы является оценка влияния температуры, состава отходов и их перемешивания на образование метана.

Для проверки факта влияния температуры и перемешивания отходов был проведен эксперимент. В качестве объекта исследования были выбраны смеси органических отходов двух типов: смесь, премущественно содержащая белки и смесь, содержащая жиры. Смеси были помещены в шприцы, которые служили в качестве реакторов (шприцы закрыты резиновой заглушкой на конце иглы) и все они находились в разных условиях:

- группа №1: температура $35^{\circ} \mathrm{C}$, смесь постоянно перемешивается;

- группа №2: температура $35^{\circ} \mathrm{C}$, шприцы с отходами неподвижны;

- группа №3: температура $25^{\circ} \mathrm{C}$, смесь постоянно перемешивается;

- группа №4: температура $25^{\circ} \mathrm{C}$, шприцы с отходами неподвижны.

В результате замеров построены графики зависимостей образования биогаза от времени в разных условиях и различных составов отходов (с белками и жирами). Время проведения исследования - 350 часов.

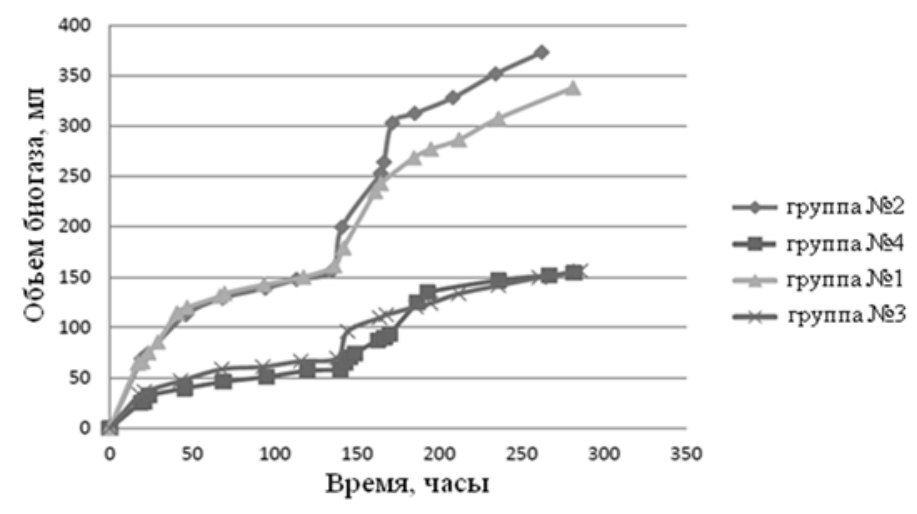

Рисунок 2 - Зависимость выхода биогаза для смеси с высоким содержанием белков.

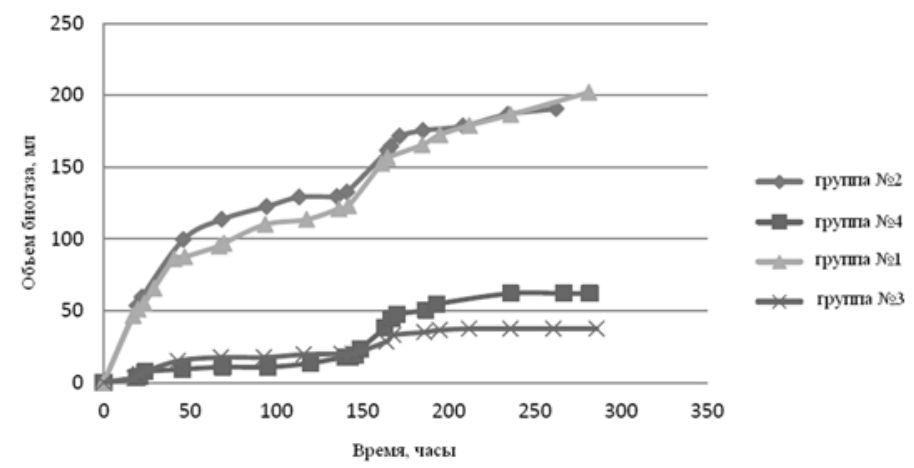

Рисунок 3- Зависимость выхода биогаза для смеси с высоким содержанием жиров.

ISPC European Technology in Science,

Malmö, Sweden
THOMSON REUTERS

Indexed in Thomson Reuters 
Был проведен еще один эксперимент на выработку биогаза из отходов. В данном случае использовались комбинированные смеси.

Состав образцов отходов.

Таблица 1

\begin{tabular}{|l|l|l|l|}
\hline Образец & Вид отходов & $\begin{array}{l}\text { Процентное } \\
\text { соотношение объемов }\end{array}$ & $\begin{array}{l}\text { Отношение } \\
\text { ХПК }\end{array}$ \\
\hline A & Углеводы и белки & $45: 55$ & $\sim 50: 50$ \\
\hline B & Углеводы и жиры & $95,5: 4,5$ & $\sim 70: 30$ \\
\hline C & Белки и жиры & $97,8: 2,2$ & $\sim 80: 20$ \\
\hline D & Белки, жиры, углеводы & $44,6: 53$, & $\sim 40: 40: 20$ \\
\hline
\end{tabular}

Смеси были помещен в реакторы, в качестве реакторов были использованы шприцы на 100 мл. Для изоляции системы от окружающей среды использованы резиновые предохранители. Условия приведения опыта: $\mathrm{t}=(30 \pm 2){ }^{\circ} \mathrm{C}$, постоянная гомогенизация. Измерение объема биогаза проводилось трижды в сутки. На седьмой день внес дополнительную порцию субстрата. Динамика образования биогаза показана на рис. 4.

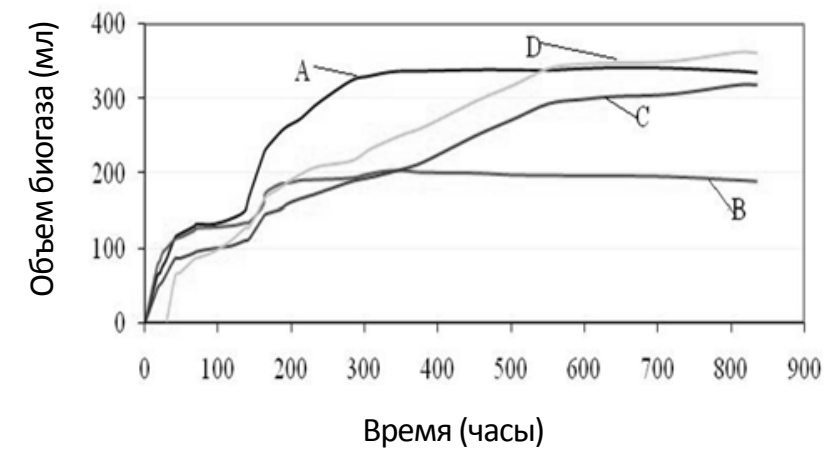

Рисунок 4 -Динамика образование биогаза для четырех видов смесей.

Производительность процесса оценивается по выходу метана (отношение ХПК газа к ХПК субстрата):

$$
Y=\frac{C O D_{\text {gas }}}{C O D_{\text {feed }}}
$$

где Y - выход газа (с англ. yield); $\mathrm{COD}_{\text {gas }}-$ химическое потребление кислорода (ХПК) для газа, мг; $\mathrm{COD}_{\text {feed }}$ - химическое потребление кислорода для субстрата, мг. Результаты расчетов на основе данных после двух недель опыта приведены в табл. 2.

Выход биогаза для всех образцов, мг/мг.

\begin{tabular}{|l|c|c|c|c|}
\hline Неделя & Образец & $\mathrm{A}$ & $\mathrm{C}$ & $\mathrm{D}$ \\
\hline $\mathrm{I}$ & 0,94 & 0,49 & 0,56 & 0,59 \\
\hline $\mathrm{II}$ & 0,95 & 0,63 & 0,47 & 0,58 \\
\hline
\end{tabular}

Измерение $\mathrm{pH}$ показало низкое значение $(5,2)$ только в образце В, в других - нейтральное. Кислая реакция среды может быть обусловлена наибольшей концентрацией жиров, которые привели к образованию жирных кислот. Кислотная или щелочная среда подавляет деятельность бактерий, и может их убить,

ISPC European Technology in Science, 
поэтому образование биогаза в образце В самое низкое.

ВЫВОДЫ. Полученные зависимости позволяют сделать вывод, что выход биогаза из смеси с высоким содержанием жиров ниже, чем из смеси с белками. Также эмиссия биогаза выше для групп при темпратуре $35^{\circ} \mathrm{C}$, чем у групп при температуре $25^{\circ} \mathrm{C}$, что подтверждает влияние температурного режима на образование метана. Исследование показывает, что состав отходов и температура оказывают большее влияние на процесс метаногенеза, чем процесс перемешивания смеси. Наибольшее количество биогаза можно получить из смеси углеводов, белков, жиров, однако производительность выработки биогаза наибольшая в растворе углеводов и белков. В образце с высоким содержанием жиров образование биогаза низкое. Итак, содержание жиров в бытовых отходах снижает производительность получения биогаза. Для эффективного анаэробного сбраживания необходим постоянный контроль уровня $\mathrm{pH}$ для предотвращения подавления деятельности бактерий в кислотной среде. Дальнейшее развитие исследований целесообразно направить на изучение образования биогаза из комбинированных составов различных отходов с учетом дополнительных факторов.

\section{References:}

1. Puhnyuk AY, Matveev YB (2007) "Biogas s polygonov otkhodov:procedura oformleniia proekta" Komunalnoe khoziajstvo, no.7, pp. 2427.

2. Yesiller N (2003) Analysis of temperatures at a municipal solid waste landfill [Electronic resource]: proceedings Sardinia 2003, Ninth International Waste Management and Landfill.

3. (1992) Der Deponiegashaushalt in Altablarerungen -Leitfaden Deponiegas: Materialien zur Altlasten-bearbeitung / [G. Rettenberger, H. Mezger, S. Urban-Kiss and partner]. - Karlsruhe: Landesanstalt fur Unweltschutz Baden-Wiirttemberg, 1992. 136.

4. Sigal IY, Kyrylyuk NI, Dombrowski EP (1997) "Problema musoroszhiganiia V Ukraine», Ekotekhnologii I resursosberezhenie, № no.1.

5. Kyrylyuk NI (1995) "Perspektivy razvitiia promyshlennykh metodov obezvrezhivaniia tverdykh bytovykh otkhodov V Ukraine" Otkhody goroda i ikh vliianie na okruzhaushchuyu sredu. Sbornik tezisov i dokladov nauchnogo seminara. [Waste of the city and its impact on the environment. Collected works of theses and reports of scientific seminar], Kyiv, pp. 7-9.

6. Shaimova AM, Nasyrova LA, Jagafarova GG, Faskhutdinov RR (2015) Alternative fuel sources - a perspective way of energy-saving [Tekst]: Intellectual Service to Oil \& Gas Industry Volume Four Jointly published by Ufa State Petroleum Technological University and Miskolc University.

7. Hobson PN, Wheatley A (1992) Anaerobic digestion modern theory and practice. London and New York: Elsevier applied science, 1992.

8. Tchobanoglous G, Burton FL, Stensel HD (2003) Wastewater engineering: treatment and reuse. Boston: McGraw-Hill, 2003.

9. Puhnyuk AY, Kucij DV, Matveev YB (2012) «Polevye issledovaniia dlia ocenki potenciala obrazovaniia biogaza na polygonakh tverdykh bytovykh otkhodov Ukrainy » Komunalnoe khoziajstvo, no.105.

10. Geletukha GG, Matveev YB, Kopejkin KA (2010) «Potencyal sbora i utilizacii svalochnogo gaza v Ukraine». Elekronnyj zhurnal energoservisnoj kompanii «Ekologicheskie sistemy» «ESKO», no. 12.

11. Gorokh NP, Babaev VN, Korinko IV (2011) «Energeticheskij potencial metanoobrazovaniia pri mezifilnom anaerobnom razlozhenii organicheskoj sostavliauschej otkhodov» Vostochno-evropejskij zhurnal peredovykh tekhnologij, no.6 (52), vol.4. 